"Follicular," or acute cryptic tonsillitis, which is the most interesting form, is not follicular at all. It is a simple or desquamative infection, due to strepto-, staphylo-, or pneumococci. It is also possibly contagious.

The pathological enlargements of the tonsil, in which a chronic process of catarrh is almost invariably present in the lacunie or crypts, form not only the best culture media for a large number of microorganisms, but give them the opportunity of invading and infecting the system. Whether micro-organisms reach the tonsil by the circulation, or, what is more probable in the vast majority of cases, through the mouth, chronically enlarged or catarrhal tonsils are a source of danger to the individual, forming one ready mode of access to the general system for micro-organisms. The treatment of such cases is obvious.

The clinical appearances alone allow us so little ground for diagnosis of simple tonsillitis from diphtheria that, in the absence of bacteriological diagnosis, we shall be wise to isolate such patients from the first, until the course of the disease renders its nature positive. This bacteriological examination is the more necessary, since the placing of patients with streptococcal pseudo-membranous throats in wards where there is dipletheria may convert a simple case into a fatal one.

Bacteriology should be the basis of the diagnosis, and no hospital or institution is complete without such an adjunct as a properly equipped laboratory. Fortunately, even if the diagnosis be in doubt, the treatment is pretty muc!l the same for all these cases, viz, antisepsis.

\title{
A NEW TONSIL PUNCH.
}

\author{
By Dr. A. B. Kelly, B.Sc., M.B. Glas.
}

Tine instrument consists essentially of a grooved body and a central sliding part, the latter carrying a punch which works into a bolster fixed on the former. To allow of more delicate manipulation two punchesfacing in opposite directions and each with its own central bar-hare

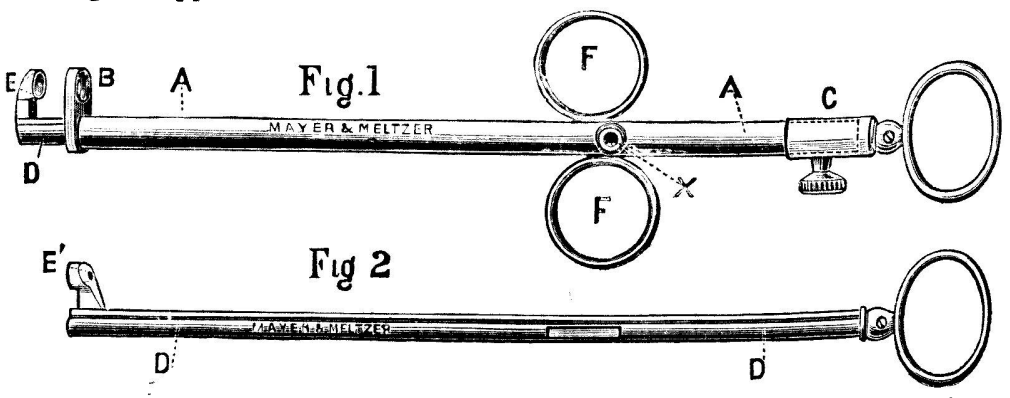

been made. For convenience they may be termed respectively the pulling and pushing punch. The body of the instrument is adapted for either. Fig. 1 represents the pulling punch complete: A $\mathrm{A}$ is the body. at one end of which the bolster ( $\mathrm{B}$ ) is fixed, while over the other the 
thumb-piece (c) is held by a screw : 1 is the central sliding bar carrying the punch (b), and into which the finger rings (F F) are screwed. Fig. 2 represents the sliding part of the puwhing punch. To change the pulling to the pushing punch the operator must remove ', unserew $\mathrm{F} \mathrm{F}$, and withdraw 1 ; then slide ${ }^{\prime}$ ' ${ }^{\prime}$ into $A . A$, and serew $\mathrm{F}$ F into the bosses $(\mathrm{x})$, one of which is on each sile of the body. The pushing punch is now complete. The changing of the punches may be effected in half a minute. The cases in which the tonsil punch may be used with adrantage are those unsuitable for tonsillotomy, and in which hitherto the galvino-cautery has been indicated. They are as follows:-1. When the tonsils are enlarged antero-posteriorly, and project but slightly, if at all, beyond the pillars of the fauces. It is naturally assumed here, as also in the cases mentioned below, that the condition of the gland is giving rise to symptoms which call for its reduction-an enlargement per se roes not justify interference. 2:. When the anterior pillar of the fiuces is stretched over the tonsil and there is danger of wounding it with the tonsillotome. 3. When, after tonsillotomy, the remaining portion of the glaml is the seat of frequently recurring attacks of inflammation. 4. When there is chronic lacunar tonsillitis, and the gland is not sufficiently cnlarged for tonsillotomy, the punch may be used alone, or together with discission. 5. When tonsillotomy is indicated, but the patient is an adult and excessively nerrous, the punch may then be used with the assurance that the local ancsthesia induced by cocaine will render its application absolutely painless. In all the above cases the tonsil punch will produce the desired result more rapidly, and with less subsequent pain and liability to severe inflammatory reaction than the galvano-cautery. The instrument is made by Messrs. Mayer and Meltzer, of 71, Great Portland Street, W.

\title{
CONGRESS MEETINGS.
}

\section{THE BRITISH LARYNGOLOGICAL AND RHINOLOGICAL ASSOCIATION.}

\author{
Eightionth Gincral Hetins, held July 13 th, IS94. \\ President-Dr. J. MACINTYRE, Glasgow, Chairman. \\ Iice-President-Dr. Norris WOLFENDEN, Tiie-Chairman.
}

Thirty-five Fellows and Visitors were present.

The minutes of the previous meeting were read and confirmed.

The following gentlemen were elected Fellows of the Association :-

Frederick SPICER, M.D., London.

Holbrook Curtis, M.D., New York.

Ciaude Wonkes, M.R.C.S., London.

Robert Fullerton, M.D., Glasgow. 